\title{
Estado de la cuestión del deber general precontractual de información y la protección al consumidor en América Latina, con énfasis en el caso chileno
}

State of the art of the pre-contractual general duty of information in Latin America, with emphasis in the Chilean case

Francisco Javier Sanz Salguero'

Fecha correspondencia:

Recibido: 14 de enero de 2020. Revisión: 18 de febrero de 2020. Aceptado: 24 de febrero de 2020.

Forma de citar:

Sanz, Francisco Javier. Estado de la cuestión del deber general precontractual de información y la protección al consumidor en américa latina, con énfasis en el caso chileno. Revista CES Derecho. Vol. 11, No. 1, enero a junio de 2020, 157-176.

\section{Open access}

Términos de uso

Licencia creative commons

Etica de publicaciones

Revisión por pares

Gestión por Open Journal System DOl: http://dx.doi.org/10.21615/ cesder.11.1.9

\section{ISSN: 2145-7719}

Sobre los autores:

1. Doctor en Derecho, Pontificia Universidad Católica de Valparaíso. Abogado, Universidad Externado de Colombia. Profesor Derecho Constitucional, Universidad Católica de Norte. Director Magíster en Derecho, Universidad Católica de Norte.

\section{Resumen}

Superar la asimetría informacional, constituye un elemento central en el tratamiento de las relaciones entre consumidores y proveedores. Con base en esta premisa, el presente estudio aborda el estado de la cuestión del deber general precontractual de información y la protección al consumidor, estudio enfocado en las principales economías de América Latina, con énfasis en el caso chileno. Adicionalmente, en el trabajo se presentan propuestas para perfeccionar los alcances de este deber general precontractual, en el contexto de la ley del consumidor chilena.

Palabras claves: Protección al consumidor, información, relación precontractual, derecho del consumidor.

\section{Abstract}

Overcoming information asymmetry is a central element in the treatment of consumer-supplier relationships. Based on this premise, the present study tackles the state of the art of the general pre-contractual information duty and consumer protection, study focused on the main economies of Latin America, with emphasis on the Chilean case. Additionally, the paper presents proposals to improve the scope of this general pre-contractual duty, in the context of the Chilean consumer law.

Keywords: Protection to Consumer, information, pre-contractual relationship, consumer rights.

\section{Introducción}

Hasta el reconocimiento de los derechos del consumidor (como conjunto de garantías que se confieren específicamente a los consumidores en sus relaciones de consumo con los proveedores de bienes y servicios [Ovalle, 2005, p. 12]), las transacciones efectuadas entre consumidores y proveedores estaban sujetas a las normas del derecho civil y comercial, las cuales se basaban en el principio de la autonomía de la voluntad o de libertad de estipulaciones, en donde cada individuo se preocupaba y respondía por sus intereses. En esta relación, se presentaba una situación de desequilibrio que 
enfrentaba al consumidor inexperto e ignorante de sus derechos, con un proveedor con mayor información y experiencia.

En el caso chileno, a fin de superar este desequilibrio, la principal razón que justifica la existencia de un régimen de protección al consumidor está fundada, precisamente, en causas de naturaleza informacional. Concretamente, estamos haciendo referencia a la existencia de una asimetría de información en las dinámicas de consumo que se desarrollan entre proveedores y consumidores, asimetría que afecta los más diversos aspectos del mercado (Gallo, 2007, p. 642)ำ y que ubica a este último (consumidor) en una posición de debilidad.

Superar la desigualdad en el tratamiento de la información en las relaciones de consumo, constituye la piedra angular en un régimen de protección al consumidor. En la normativa chilena, ese tratamiento es un tema abordado por la Ley de Protección al Consumidor (en adelante LPC) ${ }^{2}$. Sin embargo, no obstante que las reglas que imponen el suministro de información lo hacen buscando la protección de diversos intereses, la doctrina destaca un interés particular representado en la libertad contractual de los consumidores, libertad en donde las personas solo quedan vinculadas por un contrato cuando así lo deciden, decisión que debe ser libre (en el sentido que no sea coaccionada) y querida, fundada en la existencia de una información suficiente (De la Maza, 2010, p. 39).

En el contexto anterior, la LPC estipula inicialmente un deber precontractual de información, el cual apunta a la tutela de la mencionada libertad contractual y que se encuentra establecido en su artículo 3 letra b). Este deber tiene un carácter general, teniendo en cuenta que no se encuentra limitado a tipos contractuales o bienes o servicios concretos, por lo que su alcance afecta toda relación de consumo (De la Maza, 2010, p. 43).

Teniendo en cuenta su importancia en la protección de un interés privilegiado como lo es la libertad contractual, dentro del marco de las obligaciones informacionales a favor de los consumidores, en el presente trabajo enfatizamos el análisis del estado de la cuestión del deber general precontractual de información contenido en el artículo 3 letra b) de la LPC. Determinar el estado del arte respecto a la temática propuesta, implica inicialmente examinar sus orígenes en la esfera del derecho comparado hasta llegar al reconocimiento normativo nacional. Este recorrido, involucra la revisión de la obligación precontractual de informar en el modelo de la Unión Europea (dando énfasis al caso español, estudio que se justifica en virtud del tiempo que el modelo jurídico del país ibérico ha venido tratando la tutela del consumidor), hasta llegar a los sistemas normativos latinoamericanos tenidos en cuenta por el legislador chileno al momento de consagrar el deber precontractual objeto de análisis.

En el estudio apuntamos al deber general precontractual de información del proveedor en las relaciones de consumo, en virtud a que los deberes específicos que se desarrollan a partir de aquel son temas ampliamente tratados por la doctrina. En relación a este último aspecto (deberes específicos), tenemos el trabajo de autores como Antonio Catricalà y María Pia Pignalosa, además de José Antonio Corrientes Córdoba, dentro del contexto europeo; José Ovalle Favela $(2000)^{3}$, Gabriel A. Stiglitz

1. En efecto, Esta asimetría se manifiesta en todos los sectores del mercado, incluyendo materias tan variadas como la obligación general de la veracidad de las informaciones transmitidas por los medios de comunicación, la publicidad engañosa, los deberes de información en materia de contratación, entre otros ámbitos.

2. Ley № 19.496 de 1997, publicada en el Diario Oficial el 7 de marzo de 1997

3. Ovalle Favela analiza los orígenes y el contenido de la tutela del consumidor, en el marco jurídico mexicano. 
(1994) y Bruno Miragem (2016)5 , en el espectro latinoamericano; y Pablo Rodríguez Grez (Rodríguez, 2015, pp. 25-26, 29-30, 65-72, 73-74 y 75)6. Enrique Aimone Gibsón (2013, pp. 41-45, 77-84, 95-114 y 117)7. Fernando Fernández Acevedo (2013, pp. 504-512) ${ }^{8}$. Erika Isles Soto (2013, pp. 685-778) y Eduardo Escalona Vásquez (2013, pp. 813-826) ${ }^{10}$, en el ámbito jurídico chileno. Dentro del marco doctrinal de Chile, mención especial merecen los estudios de Iñigo de la Maza Gazmuri, autor que analiza diversos deberes específicos informacionales en las relaciones de consumo, incluyendo la definición de la información básica comercial (2013a , pp. 24-31); el tratamiento de la información en la relación entre los contratos de adhesión y los productos financieros (de acuerdo a lo estipulado en los artículos $17 \mathrm{~A}$ al $17 \mathrm{~F}$ de la Ley del consumidor) (2013b, pp. 376-398); y, en el ámbito de la publicidad, las materias que pueden ser objeto de inducción o engaño a través de cualquier tipo de mensaje publicitario y el tratamiento de la comunicación promocional enviada por correo electrónico (2013c, pp. 653-671 y 674-684). En este contexto, pretendemos alcanzar dos objetivos:

1.1. En primer lugar, establecer el estado de la cuestión del deber general precontractual de información del proveedor en las relaciones de consumo, dentro de la esfera de las principales economías latinoamericanas. Esta pretensión, exige examinar inicialmente los orígenes del reconocimiento formal que, en el marco europeo, se concede al carácter fundamental del derecho a la información del consumidor, dando énfasis al caso español (conforme a lo argumentado previamente).

Efectuada la anterior introducción, en el documento pasamos a revisar el tratamiento del deber general precontractual de información en los sistemas normativos más representativos dentro del espectro de la defensa al consumidor en América Latina, sistemas cuyo impacto se hace manifiesto al encarnar a las mayores economías en esta subregión. Bajo esta perspectiva, comenzamos el estudio con el caso de Brasil (como precursor en América Latina en este ámbito), hasta llegar a los casos de México, Argentina y Perú. Concluimos esta parte examinando el caso chileno, a fin de contrastarlo con los modelos jurídicos antes revisados.

2.2. Con base en los resultados del estudio jurídico comparado y nacional, un segundo objetivo del artículo consiste en formular propuestas que permitan avanzar en el perfeccionamiento del deber general precontractual de información, dentro del marco de la defensa del consumidor en Chile.

4. Desde el punto de vista del derecho Argentino, Stiglitz es el primer autor en realizar un amplio estudio de la Ley de defensa del consumidor Argentina aprobada en 1993 (Ley N² 24.240), análisis que incluye (en lo que concierne a los deberes específicos en la esfera informacional) la revisión del control de la publicidad.

5. Miragem, profundiza el tratamiento de los derechos del consumidor dentro del marco de la legislación brasileña.

6. Entre los deberes específicos a favor del consumidor tratados por el autor, tenemos la obligación de información en los contratos celebrados por medios electrónicos, catálogos, avisos o a distancia; la obligación de información sobre productos con deficiencias, usados o refaccionados o integrados con partes o piezas usadas; el vínculo entre la información y la publicidad, y el tratamiento de las promociones y ofertas; y la información sobre las condiciones de crédito al consumidor.

7. Los deberes específicos en la esfera informacional analizados por este autor, incluyen las promociones y ofertas; el tratamiento de la rotulación (con énfasis en la composición nutricional de los alimentos y su publicidad); la publicidad engañosa (con énfasis en los mecanismos publicitarios que involucren nuevas tecnologías, incluyendo el spam y el teaser) y su tratamiento jurisprudencial; y el deber de informar dentro del espectro de los productos defectuosos.

8. Como deber específico informacional en el ámbito de los servicios o productos financieros, Fernández Acevedo se concentra en el tratamiento sancionatorio aplicado a los proveedores que induzcan en error o engaño al consumidor.

9. En el ámbito de la publicidad, esta autora analiza diversos temas: el derecho a la información y su relación con la rotulación, el tratamiento de la información del precio, la suspensión de emisiones publicitarias, el formato de la información comercial, el carácter comprobable que debe exigirse a la información consignada y el tratamiento de la medida prejudicial probatoria en caso de publicidad falsa o engañosa.

10. Escalona Vásquez aborda las obligaciones del proveedor de informar en la esfera del crédito al consumidor. 


\section{Orígenes del reconocimiento del deber general precontractual de información y la protección al consumidor}

\subsection{El deber de información y la protección al consumidor en Europa}

No obstante que desde la primera mitad del siglo XX se presentaron los primeros movimientos de los consumidores (los que reclamaron nuevas regulaciones sobre cuestiones específicas, particularmente en los Estados Unidos), e incluso en el año de 1962 el presidente John F. Kennedy propuso al derecho a ser informado como un derecho fundamental (Ovalle, 2005, pp. 77-78), solo hasta mediados de la década de los setenta se generó un reconocimiento formal del carácter fundamental del derecho a la información del consumidor. Este hito, ocurrió en Europa en el año de 1975 (Piris, 2000, p. 4), con la redacción del Programa preliminar de la Comunidad Económica Europea para una política de protección e información a los consumidores, en adelante "Programa Preliminar". El contenido de este programa, se vería reforzado por las Directrices de la ONU para la protección al consumidor de 1985 (en adelante Directrices de la ONU) (Ovalle, 2000, p. 3).

En este contexto, el "Programa Preliminar" (al reordenar de forma sistemática todas las iniciativas para la tutela del consumidor en la Unión Europea) reconoció el carácter fundamental del derecho a la información del consumidor ${ }^{11}$, teniendo en cuenta que el comprador de bienes o servicios debe disponer de una información suficiente que le permita conocer sus características (incluyendo naturaleza, calidad, cantidad y precio) y efectuar una elección racional entre productos y servicios competitivos, entre otras garantías ${ }^{12}$. Respecto a las Directrices de la ONU, estas reconocieron de forma implícita como derecho fundamental de los consumidores, el acceso a una información adecuada que les permita hacer elecciones bien fundadas conforme a los deseos y necesidades de cada cual (ONU, 2016, pp. 6-7).

Desde una perspectiva histórica, al contrastar las disposiciones anteriores con la normativa española, encontramos que esta última tiene la virtud de haber dado tratamiento al derecho a la información del consumidor de manera previa, puntualmente a partir de la década de los sesenta del siglo pasado ${ }^{13}$, destacándose el caso de la Ley 57/1968, reguladora de la percepción de cantidades anticipadas en la construcción y venta de viviendas, norma que surgió ante la necesidad de evitar fraudes, engaños, y manipulaciones, además de obtener la satisfacción del consumidor en la elección de los productos y servicios en el sector inmobiliario (Sánchez de Diego, 2009, p. 3). Esta situación, justifica continuar el estudio planteado a partir del modelo jurídico español, como lo hacemos en la siguiente parte.

\subsection{Estado de la cuestión del deber general precontractual de información y la protección} al consumidor: situación en España

En la legislación española, el estado de la cuestión en el tratamiento del deber general precontractual de información en materia de protección al consumidor, exige ser examinado a partir del Real Decreto Legislativo $1^{\circ}$ del 16 de noviembre de 2007, por el que se aprueba el texto refundido de la Ley General para la Defensa de los Consumidores y Usuarios"14, en adelante LGDCU. Con base en la citada LGDCU, estudiaremos este deber de informar desde la perspectiva de la defensa del consumidor en el Estado ibérico.

11. Los otros derechos fundamentales del consumidor reconocidos por el "Programa Preliminar" abarcan la salud y seguridad, sus intereses económicos, protección de los daños, la educación y el derecho a la representación.

12. Conforme a lo expresado en la Resolución del Consejo del 14 de abril de 1975 relativo a un programa preliminar de la CEE para una política de protección e información a los consumidores.

13. Incluso antes que la Asamblea Consultiva del Consejo de Europa editara la Carta Europea de Protección al Consumidor (base del enunciado "Programa preliminar"), lo cual ocurrió en 1972.

14. Publicado en el Boletín Oficial del Estado número 287, de 30 de noviembre de 2007. 
2.2.1. Reconocimiento normativo del deber general precontractual de información a favor del consumidor

En España, este particular deber general de información es abordado por la LGDCU en la letra d) artículo $8^{\circ}$, norma que incluye entre los derechos básicos de los consumidores y usuarios, a la "información correcta sobre los diferentes bienes o servicios y la educación y divulgación para facilitar el conocimiento sobre su adecuado uso, consumo o disfrute".

\subsubsection{Comentarios al tratamiento del deber general precontractual de información a favor del consumidor}

El deber general de información a favor del consumidor consagrado en el mencionado artículo $8^{\circ}$ de la LGDCU, tiene un sustento constitucional en el apartado segundo artículo 51 de la Carta Política española. No obstante que algunas legislaciones europeas reconocen directamente el carácter fundamental del derecho a la información (como ocurre con el Codice del consumo italiano ${ }^{15}$, en donde este derecho fundamental se desarrolla normativamente en deberes de informar específicos [Pasa, 2007, p. 1308]16), la Constitución española, al encargarse de los principios rectores de la política social y económica, concede un carácter más amplio a este derecho, al establecer que los "poderes públicos" (Nieto, 1986, pp. 23-24) deben promover la información y la educación de los consumidores y usuarios ${ }^{18}$. Para la doctrina, está promoción fundamental de la información y la educación se justifica, teniendo en cuenta que en la sociedad actual la oferta de los bienes de consumo se ha ido concentrando en manos de grandes sociedades (con frecuencia multinacionales), que desde posiciones privilegiadas (a partir de la formalización de sus relaciones jurídicas con los consumidores a través de los contratos de adhesión) han colocado al consumidor en una situación de indefensión (Prada, 1998, p.37).

Con base en el reconocimiento constitucional, el derecho de la información de los consumidores sería incluido en la Ley 26/1984 General Defensa de los Consumidores y Usuarios $^{19}$, hasta llegar al texto refundido del año 2007 (LGDCU). Sin embargo, antes de la aprobación de la Carta Política española de 1978, ya se observa un tratamiento de este derecho en particular, destacándose el caso de la Ley 57/1968 (estatuto anterior al "Programa Preliminar" europeo) previamente explicada.

Teniendo como punto de partida el principio contenido en el apartado $2^{\circ}$ artículo 51 de la Constitución española, la obligación de informar a los consumidores se ha caracterizado por su extenso tratamiento tanto en el ámbito de las normativas estatales, como en el campo de la propia LGDCU. Este tratamiento, se desarrolla dentro de los siguientes hitos:

En primer lugar, tenemos la incorporación de previsiones que, en el marco del deber general de información al consumidor, se han adoptado en diversas normativas estatales, a fin de que el mandato constitucional sea cumplido debidamente. En este ámbi-

\footnotetext{
15. En efecto, el Codice del consumo italiano en su artículo $2^{\circ}$ letra c), establece que "a los consumidores y usuarios son reconocidos como fundamentales los derechos:" [...] "b) a una información adecuada y a una publicidad correcta (la traducción es nuestra). El texto original de la norma reza: 2. Ai consumatori ed agli utenti sono riconosciuti come fondamentali $i$ diritti: [...] c) ad una adeguata informazione e ad una corretta pubblicità.

16. Precisamente, el derecho fundamental reconocido en el artículo $2^{\circ}$ letra c) del Codice del consumo, se desarrolla normativamente en deberes de informar específicos en la Parte II del mismo estatuto legal. En este segmento, el núcleo de normas de mayor relieve atañe a la información que debe proporcionarse al consumidor, aspectos tratados entre los artículos 4 al 12 del Codice: proceda de donde proceda, ésta debe adecuarse a la técnica de comunicación utilizada y debe expresarse de manera clara y comprensible, teniendo siempre en cuenta la modalidad de conclusión del contrato o las comunicación utilizada y debe expresarse de manera clara y comprensible, teniendo siempre en cuenta la mín
características del sector, con la finalidad de garantizar que el consumidor toma conocimiento de la misma.

17. De acuerdo a la doctrina, el ámbito de los poderes públicos que son destinarios de la norma, incluye tanto al poder estatal, como autonómico o local, lo que impone la necesaria amortización entre sus legislaciones.

18. Concretamente, el inciso 2 del citado artículo 51 estipula que "los poderes públicos promoverán la información y la educación de los consumidores y usuarios, fomentarán sus organizaciones y oirán a éstas en las cuestiones que puedan afectar a aquéllos, en los términos que la ley establezca".

19. Puntualmente, esta ley al consagrar los derechos básicos de los consumidores, incluye el derecho a la información correcta sobre los diferentes productos o servicios, y la educación y divulgación, para facilitar su adecuado uso, consumo o disfrute [apartado $1^{\circ}$ letra d) artículo $1^{\circ}$ ].
} 
to, podemos incluir estatutos como el Real Decreto Legislativo de 21 de abril de 1989 , sobre protección a los consumidores en cuanto a la información a suministrar en la compraventa y arrendamiento de viviendas (artículos 4, 5 y 10), y la Ley de Aprovechamiento por Turnos de Bienes Inmuebles, de 15 de diciembre de 1998 (artículo 8), entre otras disposiciones (Zurilla, s.d., pp. 2-3) 20.

En segundo lugar, la LGDCU, además del deber general precontractual de informar a consumidores y usuarios estipulado en su letra d) artículo $8^{021}$, desarrolla deberes específicos a lo largo de su articulado. A este respecto, tenemos el artículo 12, norma enfocada a la información sobre "los riesgos susceptibles de provenir de una utilización previsible", y la información sobre productos químicos o que lleven sustancias peligrosas; el artículo 17, norma que encarga a los poderes públicos y a los medios de comunicación social de titularidad pública estatal, diversos roles en materia de formación y educación de los consumidores y usuarios en la esfera de lo informacional; finalmente, el artículo 60 de la LGDCU establece las características ${ }^{22}$ y la naturaleza ${ }^{23}$ de la información que el empresario debe suministrar al consumidor o usuario, especialmente en lo que respecta a las condiciones jurídicas y económicas del contrato que pretende suscribirse (Zurilla, s.d., pp. 5-6) ${ }^{24}$.

\section{El deber general precontractual de información y la protección al consumidor, dentro del marco de las mayores economías de América Latina}

Transcurridos 15 años de la elaboración del "Programa Preliminar" europeo, la primera legislación de América Latina en reconocer formalmente la importancia de informar a los consumidores, es la normativa de Brasil, con la promulgación del Código de Defesa do Consumidor de 1990. A partir de este hito, otros modelos regionales adoptarían figuras jurídicas análogas, incluyendo los casos de México (1992), Argentina (1993), Perú (2010) y Chile (1997), Estados que paralelamente encarnan las mayores economías en el espectro latinoamericano, conforme las estadísticas del Banco Mundial (2018). Siguiendo este orden de prelación (partiendo por ello desde el Estado con la economía más robusta, como lo es Brasil), a continuación revisamos el tratamiento del deber general precontractual de información a favor del consumidor, a partir de su reconocimiento normativo en cada uno de estos países.

\subsection{Estado de la cuestión del deber general precontractual de información y la protección al consumidor: situación en Brasil}

En la normativa brasileña, el estado de la cuestión en el tratamiento de este deber precontractual de información en materia de defensa al consumidor, debe ser examinado con base en el Código de Defesa do Consumidor de 1990, en adelante CDC ${ }^{25}$. A continuación, a partir del citado Código estudiaremos este deber de informar, teniendo en cuenta que Brasil es pionero en América Latina en este ámbito del derecho, siendo además la economía más robusta de la subregión.

20. Otros textos legales que, según la doctrina, adoptan previsiones al efecto de que el mandato constitucional de información del consumidor sea cumplido debidamente (algunos actualmente vigentes y otros ya derogados), son los siguientes: Ley de Crédito al Consumo de 23 de marzo de 1995 (artículos 16 y 17); Ley de Ordenación del Comercio Minorista de 15 de enero de 1996 (artículos 39 y 40); Ley de Venta a Plazos de Bienes Muebles, de 13 de julio de 1998 (artículos 7 y 14); Ley Orgánica de 13 de diciembre de 1999, de Protección de Datos de Carácter Personal (artículo 5); Ley de Servicios de la Sociedad de la Información y Comercio Electrónico, de 11 de julio de 2002 (artículos 10 y 27); Ley sobre comercialización a distancia de servicios financieros, de 11 de julio de 2007 (artículos 7 y 8); y Ley 43/2007, de protección de los consumidores y usuarios en la contratación de bienes con oferta de restitución (artículos 2 y 3).

21. Garantía reforzada con el derecho a la educación y la divulgación necesaria para facilitar el conocimiento de la información, a fin de alcanzar el uso consumo o disfrute de los bienes y servicios, según reza la misma norma.

22. La información debe ser clara, comprensible y adaptada a las circunstancias.

23. Información relevante, veraz y suficiente.

24. Otras normas vinculadas con el derecho a la información o usuario, reconocidas por la doctrina dentro del marco de la LGDCU, son el apartado $2^{\circ}$ artículo 61 (que reconoce el principio de integración de la publicidad), el artículo 97 (que complementa el artículo 60 referido al ámbito precontractual) y el artículo 49, entre otros.

25. Código aprobado por la Lei № 8.078 , del 11 de septiembre de 1990 
3.1.1. Reconocimiento normativo del deber general precontractual de información a favor del consumidor

En la legislación brasileña, este deber precontractual de información es reconocido por el CDC en su artículo $6^{\circ}$ fracción III, norma que incluye entre los derechos básicos de los consumidores 26 "la información adecuada y clara sobre los diferentes productos y servicios, con especificación correcta de cantidades, características, composición, calidad, tributos incidentes y precio, así como sobre los riesgos que presenten"27.

\subsubsection{Comentarios al tratamiento del deber general precontractual de información a} favor del consumidor

No obstante que la defensa general del consumidor tiene un sustento constitucional en el artículo $5^{\circ}$ numeral 31 de la Carta Política de Brasil de $1988^{28}$, el deber general precontractual de información a favor del consumidor consagrado en el CDC se origina en dos normativas con alcance europeo y global, respectivamente: el citado "Programa preliminar" europeo de 1975 y las Directrices de la ONU de 1985 (Ovalle, 2000, pp. 17-18).

Con base en el carácter fundamental otorgado al derecho a la información del consumidor por parte del "Programa Preliminar" de 1975, en asocio con lo dispuesto por las Directrices de la ONU de $1985^{33}$, en la normativa de Brasil podemos identificar dos objetivos que pretenden ser alcanzados con el reconocimiento del derecho esencial del consumidor a ser informado. Un primer objetivo, consiste en lograr la mayor transparencia en las relaciones comerciales, buscando ampliar las posibilidades de elección de los consumidores (Roscoe y Faiad de Moura, 2014, p. 91). Un segundo objetivo (estrechamente ligado al anterior), implica superar el déficit informacional entre el consumidor y el proveedor, teniendo en cuenta que este último posee un mayor conocimiento de los datos de las personas y de los procesos involucrados en la producción y suministro de bienes servicios (Miragem, 2016, p. 214).

Para que la protección al deber general precontractual de información consagrado en el CDC sea eficaz, no basta con la simple indicación de datos al consumidor: es necesario que esta información sea debidamente entendida por sus destinatarios. Para la doctrina, alcanzar esta debida comprensión exige combinar el deber de informar con otros elementos derivados de la buena fe objetiva, como por ejemplo el deber de colaboración y de respeto a la contrapartida, lo que se traduce en la presencia de un deber de informar con veracidad (Miragem, 2016, p. 215).

En cuanto a sus alcances, el deber general de información reconocido al consumidor tiene un amplio desarrollo normativo en el CDC, estableciéndose una serie de obligaciones y garantías en materia estrictamente informacional a cargo del proveedor y a favor de la parte más débil, en las distintas fases de las relaciones de consumo. En este sentido, tenemos el tratamiento de diversos temas (Miragem, 2016, p. 214): la información sobre riesgos y peligrosidad ${ }^{29}$; los defectos de información ${ }^{30}$; los vicios de la información ${ }^{31}$; la eficacia vinculante de la información, su equiparación a la oferta y la propuesta y las consecuencias de la violación del deber de informar ${ }^{32}$; el deber

26. El texto original de la norma dice: Art $6^{\circ}$ São direitos básicos do consumidor (I) III - a informacão adequada e clara sobre os diferentes produtos e serviços, com especificação correta de quantidade, características, composição, qualidade, tributos incidentes e preço, bem como sobre os riscos que apresentem. 27. La traducción es nuestra.

28. Concretamente este numeral 31 (el cual hace parte de las normas que reconocen derechos fundamentales de naturaleza colectiva) estipula que "el Estado promoverá, en la forma de la ley, la defensa del consumidor"

29. Artículo $8^{\circ}, \mathrm{CDC}$

30. Artículos 12 y 14 , CDC

31. Artículos 18 y 20, CDC

32. Artículos 30, 31, 33,34 y 35, CDC 
de informar en la publicidad ${ }^{33}$; la ineficacia en relación con el consumidor de las disposiciones contractuales no informadas ${ }^{34}$; los alcances del concepto de cláusula abusiva, respecto de aquellas que no fueron suficientemente informadas al consumidor ${ }^{35}$; y las obligaciones específicas de información en los contratos ${ }^{36}$.

Finalmente y como una novedad normativa, la Lei 12.741 de 2012 modificó el artículo $6^{\circ}$ fracción III del CDC, incorporando entre las informaciones que deben ser entregadas al consumidor (además de las originalmente anotadas en el citado artículo) las relativas a los tributos incidentes.

\subsection{Estado de la cuestión del deber general precontractual de información y la protección} al consumidor: situación en México

En la normativa mexicana, el estado de la cuestión en el tratamiento de este deber general de información, se explica a partir del estudio de la Ley federal de protección al consumidor de 1992, en adelante LFPC ${ }^{37}$. Con base en esta ley federal y siguiendo con el orden de prelación propuesto (ya que México es la segunda economía más robusta de América Latina), revisamos este deber de informar.

\subsubsection{Reconocimiento normativo del deber general precontractual de información a favor del consumidor}

En la legislación mexicana, el deber general precontractual de información dentro del marco de protección al consumidor, es recogido por la LFPC en su artículo $1^{\circ}$ fracción III, norma que incluye entre los derechos básicos en las relaciones de consumo, la "información adecuada y clara sobre los diferentes productos y servicios, con especificación correcta de cantidad, características, composición, calidad y precio, así como sobre los riesgos que representen".

\subsubsection{Comentarios al tratamiento del deber general precontractual de información a favor del consumidor}

Si bien la protección general del consumidor tiene un sustento constitucional en el artículo 28 párrafo $3^{\circ}$ de la Carta Política mexicana ${ }^{38}$, el deber general precontractual de información a favor del consumidor consagrado en la LFPC tomó como base el artículo $6^{\circ}$ del CDC brasileño ${ }^{39}$, norma que consagra los "derechos básicos" del consumidor. A este respecto, hay que anotar que mientras el estatuto del Brasil habla de "derechos básicos", la LFPC sustituyó esta expresión por la de "principios básicos", cambio que la doctrina no considera acertado, teniendo en cuenta dos factores. Por un lado, la ley mexicana recoge los derechos fundamentales señalados en el "Programa Preliminar" europeo de 1975 y en las Directrices de la ONU de 1985, además de los mencionados derechos básicos del estatuto del consumidor del Brasil. Por otro lado, la expresión "principios básicos" utilizados en la LFPC, no parece corresponder con el sentido de los "principios generales del derecho" establecidos en el artículo 14 párrafo cuarto de la Constitución mexicana. Se concluye entonces que el artículo $1^{\circ}$ de la LFPC le reconoce al derecho a la información el carácter de derecho básico (Ovalle, 2000, pp. 19-20), siendo el primero de los siete derechos básicos que la legislación de este país establece en materia de defensa de los consumidores (Universidad Interamericana para el Desarrollo, s.d., pp. 4-5).

33. Artículo 36, CDC.

34. Artículo 46, CDC.

35. Artículo 51, CDC.

36. Artículos 54 y $55, \mathrm{CDC}$

37. Publicada en el Boletín Oficial de la Federación el 24 de diciembre de 1992.

38. Concretamente, la parte final del párrafo $3^{\circ}$ estipula que "la ley protegerá a los consumidores y propiciará su organización para el mejor cuidado de sus intereses".

39. Puntualmente la fracción III de este artículo, en donde se reconoce como uno de los derechos básicos del consumidor "la información adecuada y clara sobre los diferentes productos y servicios, con especificación correcta de cantidades, características, composición, calidad y precio, así como sobre los riesgos que presenten". 
A partir de las facultades otorgadas por la LFPC, México tiene la particularidad de contar con dos autoridades encargadas de hacer efectivo el derecho general a la información consagrado en el artículo $1^{\circ}$ fracción III. En primer lugar, tenemos la Secretaría de Comercio y Fomento Industrial (SECOFI), dependencia del Poder Ejecutivo Federal cuya facultad principal en aras de la tutela del deber de información, consiste en expedir normas oficiales de carácter nacional, respecto de productos que "deban expresar los elementos, substancias o ingredientes de que estén elaborados o integrados así como sus propiedades, características, fecha de caducidad, contenido neto y peso o masa drenados, y demás datos relevantes en los envases, empaques, envolturas, etiquetas o publicidad, que incluyan los términos y condiciones de los instructivos y advertencias para su uso ordinario y conservación" 40 . En segundo lugar, tenemos la Procuraduría Federal del Consumidor (Profeco) ${ }^{41}$, autoridad administrativa cuyas atribuciones en este ámbito son las de "recopilar, elaborar, procesar y divulgar información objetiva para facilitar al consumidor un mejor conocimiento de los bienes y servicios que se ofrecen en el mercado" (Procuraduría Federal del Consumidor, s.d., pp. 7-8) ${ }^{42}$, así como la de elaborar estudios en materia de calidad de bienes y servicios ${ }^{43}$, los cuales pueden formar parte de dicha información (Ovalle, 2000, pp. 30-31). En este contexto, al contrastar las competencias de las dos autoridades, de observa que la primera (SECOFI) asume el rol de coordinación de la segunda (Profeco), lo que debería redundar en una labor más efectiva en la tutela del deber general examinado.

Finalmente, con fundamento en el principio según el cual la información plena sobre los productos y servicios es esencial para poder realizar un acto de elección de manera consciente, el deber general de información reconocido en la LFPC se desarrolla legalmente en el Capítulo III del mismo texto normativo ${ }^{44}$.

No obstante lo anterior, en la praxis jurídica mexicana (y como consecuencia del acelerado desarrollo tecnológico y la introducción de nuevos productos y riesgos), el derecho a la información en estudio es una demanda aun no cumplida a cabalidad, lo cual se confirma al comparar el ejercicio de este derecho en México respecto a otras regiones (Asociación El Poder del Consumidor, 2020). Como manifestación de esta deficiencia, tenemos el tratamiento del etiquetado de productos que contienen transgénicos. En efecto, mientras que en la Unión Europea los consumidores pueden ejercer su derecho a elegir entre productos que contienen transgénicos y los que no los contienen (ya que están sometidos a un severo régimen de etiquetado) (Fernández et al, 2004, p. 113), en México este derecho en particular no existe porque no se ha impuesto el etiquetado a los productos que contienen transgénicos o sus derivados, de forma análoga a lo que ocurre con la normativa de los Estados Unidos (Edicom Data, s.d. $)^{45}$.

3.3 Estado de la cuestión del deber general precontractual de información y la protección al consumidor: situación en Argentina

Continuando con el orden de prelación de las economías más importantes de la subregión, en el sistema jurídico argentino este deber general precontractual de información es abordado por la Ley № 24.240 de 1993, o "Ley de defensa del consumidor" 46 . En la norma, este derecho del consumidor a ser informado representa su

41. A este organismo se le confieren funciones de autoridad administrativa, y está encargado de promover y proteger los derechos e intereses del consumidor, procurando además la equidad y seguridad jurídica en las relaciones entre proveedores y consumidores.

42. Artículo 24 fracción IV de la LFPC.

43. Artículo 24 fracción $X$ de la LFPC.

44. Este Capítulo III, se desarrolla entre los artículos 32 a 45 de la LFPC.

45. En efecto, esta ausencia normativa en materia de etiquetado también está presente en el régimen jurídico de los E.U., en donde no es obligatorio etiquetar los alimentos transgénicos porque son considerados iguales que los otros. Esta realidad no sorprende, teniendo en cuenta que esta nación es la que más hectáreas dedica a los cultivos transgénicos a nivel global.

46. Ley sancionada el 22 de setiembre de 1993. 
columna vertebral, aspecto que tendría incidencia en la aprobación del estatuto del consumidor chileno años más tarde (Pavan, 1997, p. 29) ${ }^{47}$. Este grado de reconocimiento del rol de ese deber a favor del consumidor, y su desarrollo normativo, son temas tratados extensamente por la doctrina Argentina, aspectos que abarcamos a continuación.

3.3.1. Reconocimiento normativo del deber general precontractual de información a favor del consumidor

En la legislación en estudio, este deber general de información es incorporado por la "Ley de defensa del consumidor" en su artículo $4^{\circ}$, disposición que define la obligación del proveedor de entregar información al consumidor y sus características, en los siguientes términos:

"Artículo $4^{\circ}$ - Información. El proveedor está obligado a suministrar al consumidor en forma cierta, clara y detallada todo lo relacionado con las características esenciales de los bienes y servicios que provee, y las condiciones de su comercialización.

La información debe ser siempre gratuita para el consumidor y proporcionada en soporte físico, con claridad necesaria que permita su comprensión. Solo se podrá suplantar la comunicación en soporte físico si el consumidor o usuario optase de forma expresa por utilizar cualquier otro medio alternativo de comunicación que el proveedor ponga a disposición"48.

La norma en comento, se desarrolla en conjunto con una serie de disposiciones especiales que regulan la información debida al consumidor, y que abarcan temas como la lealtad informacional en las relaciones comerciales y de servicios ${ }^{49}$, el tratamiento de la publicidad dentro del ámbito del consumo humano $0^{50}$, y la prohibición de inducir a la automedicación en relación a los fármacos de venta libre ${ }^{51}$, entre otras materias (Stiglitz, 1994, p. 63).

3.3.2. Comentarios al tratamiento del deber general precontractual de información a favor del consumidor

El deber de general de información consagrado en el artículo $4^{\circ}$, tiene un sustento constitucional en el artículo 42 de la Carta Política Argentina. En efecto, esta Constitución en su parte dogmática consagró los derechos de los consumidores y usuarios, reconociéndole a estos el derecho en la relación de consumo "a una información adecuada y veraz" 52 .

Ya durante la construcción de la "Ley de defensa del consumidor", la necesidad de consagrar este deber general se justificó en la existencia de una asimetría de información en las dinámicas de consumo que se desarrollaban entre proveedores y consumidores, lo que ocasionaba un estado de debilidad de este último en esa relación, procurándose otorgar a la parte menos favorecida (consumidor) los remedios legales que permitiesen resguardar su integridad física y patrimonial (Baistrocchi y Rodríguez, 1991, p. 226).

47. La filosofía semejante entre la "Ley de defensa del consumidor" argentina de 1993 y la Ley de Protección al Consumidor chilena de 1997, es un aspecto identificado por el Instituto Nacional de la Administración Pública argentino, al efectuar un análisis comparativo de los sistemas de Argentina, Brasil y Chile. 48. El artículo $4^{\circ}$ original, fue sustituido por artículo $1^{\circ}$ de la Ley $N^{\circ} 27.250$ del 2016.

49. Artículo 12, letra j), Ley $\mathrm{N}^{\circ} 22.802$ de 1983

50. Artículos 221, 222 y 235 quinto número 3-10.5, Código Alimentario Argentino (Ley No 18.284 de 1969).

51. Artículo 5 y 19, Ley $N^{\circ} 16.463$ de 1964.

52. Otros derechos reconocidos por el artículo 42 de la Constitución Nacional Argentina a los consumidores y usuarios en las relaciones de consumo, son los siguientes: protección de su salud, seguridad e intereses económicos; a la libertad de elección, y a condiciones de trato equitativo y digno; al control de los monopolios naturales y legales, y al de la calidad y eficiencia de los servicios públicos. 
Actualmente, para la doctrina argentina el deber general precontractual de informar tiene su sustento en la necesidad de evitar la situación de desigualdad, en la que una de las partes está informada y la otra desinformada sobre un determinado hecho, lo que ejerce influencia en el consentimiento de ésta última y la puede llevar a contratar en condiciones desfavorables. En complemento a esta opinión y desde la perspectiva de la jurisprudencia de este país ${ }^{53}$, una de las prerrogativas fundamentales que se reconoce a los particulares en el ámbito de las relaciones de consumo, radica en el derecho a ser nutrido de elementos ciertos y objetivos, detallados, eficaces y suficientes, sobre las características esenciales del producto objeto de la contratación (Baistrocchi y Rodríguez, 1991, p. 226).

Finalmente, dentro del trabajo de la doctrina (partiendo de la premisa conforme a la cual el derecho a ser informado es un derecho sustancial y representa la columna vertebral de la "Ley de defensa del consumidor" [Proconsumer, s.d.]), el artículo $4^{\circ}$ establece como elementos característicos esenciales de la información que debe suministrarse, los siguientes (Bagalá, s.d.) ${ }^{54}$ :

En primer término, el carácter de "cierta" y "detallada", que debe tener la información. Este factor, determina una exigencia para el proveedor, que consiste en proporcionar a la parte débil de la relación de consumo una información veraz, a fin de que el consumidor tenga conocimientos reales al momento de adquirir un bien o contratar un servicio, lo que le permite actuar, adoptar o posibilitar, con prudencia y responsabilidad, una correcta decisión (Proconsumer, s.d.). Este carácter "cierto" y "detallado" de la información, también está consagrado en el artículo 1100 del Código Civil y Comercial de la Nación ${ }^{55}$, norma igualmente referida al deber de información y que coexiste con el artículo $4^{\circ}$ de la "Ley de defensa del consumidor".

En segundo lugar, el carácter de "clara" que debe tener la información. Este factor, le permite al consumidor comprender de manera adecuada su contenido. El objetivo de la claridad a fin de lograr la comprensión de la información, es una condición expresamente reconocida en la parte final del precitado artículo 1100, sentido que también podemos aplicar al carácter de "claro" estipulado en el artículo $4^{\circ}$ de la "Ley de defensa del consumidor".

Adicionalmente, la naturaleza gratuita que debe tener la información. Esta gratuidad tiene un carácter sustancial, ya que la eventual onerosidad en la entrega de los datos y características, al momento de adquirir un bien o contratar un servicio, profundizaría la asimetría de información en las dinámicas de consumo que se generan entre proveedores y consumidores.

3.4. Estado de la cuestión del deber general precontractual de información y la protección al consumidor: situación en Perú

No obstante que desde la promulgación del Decreto Legislativo 716 de 1991 se dio tratamiento (aunque de forma incipiente) a los derechos del consumidor, y pese a las reformas legales generadas con posterioridad (Durand, 2004, pp. 135-136) ${ }^{56}$, en el régimen jurídico peruano solo hasta el año 2010 comenzó a regir un régimen sistematizado con el actual "Código de protección y defensa del consumidor" (en adelante

53. Desde la perspectiva del sistema de protección al consumidor reconocido en el artículo 42 de la Carta Política Argentina.

54. Básicamente, la obligación de información encierra dos aspectos: uno negativo (abstenerse de dar información errónea) y otro positivo (el de transmitir toda la información exigible).

55. Aprobado por la Ley 26.994, y promulgado según Decreto 1795/2014.

56. Entre las reformas para destacar, tenemos las generadas con el Decreto Legislativo 807 de 1996, la Ley 27311 del 2000 (o "Ley de Fortalecimiento del

Sistema de Protección del Consumidor"), el Decreto Supremo 039-2000-ITINCI del 2000 (que sancionó el Texto Único Ordenado de la Ley Protección del

Consumidor, consolidando en este último texto todas las teorías principios, instituciones y derechos del consumidor) y la Ley 27917 del 2003 , entre otras. 
Cpdc) ${ }^{57}$. En este sentido, el deber general precontractual de información dentro del marco de protección al consumidor debe estudiarse a partir de este Código, destacando que algunas manifestaciones del derecho a ser informado habían sido reguladas previamente y de forma dispersa en diversos textos normativos ${ }^{58}$.

\subsubsection{Reconocimiento normativo del deber general precontractual de información a favor} del consumidor

En la legislación peruana, este deber de información es reconocido por el Cpdc en el artículo $1^{\circ}$ número 1.1 letra b) ${ }^{59}$, consagrando como uno de los derechos del consumidor, el "derecho a acceder a información oportuna, suficiente, veraz y fácilmente accesible, relevante para tomar una decisión o realizar una elección de consumo que se ajuste a sus intereses, así como para efectuar un uso o consumo adecuado de los productos o servicios".

\subsubsection{Comentarios al tratamiento del deber general precontractual de información a favor del consumidor}

El deber general de información a favor del consumidor consagrado en el artículo $1^{\circ}$, tiene un sustento constitucional en el artículo 65 de la Carta Política peruana. En efecto, esta Constitución, al consagrar los principios generales del régimen económico, defiende el interés de los consumidores y usuarios garantizando "el derecho a la información sobre los bienes y servicios que se encuentran a su disposición en el mercado" (Reyes y García, 2016, pp. 172, 181 y 182)60.

De manera análoga a lo que sucede en otras legislaciones, la necesidad de garantizar la información al consumidor pretende, entre sus objetivos, superar la situación de desventaja en que éste se encuentra frente al proveedor (Maraví, 2013, p. 33), o asimetría informativab1.

Concentrándonos en los elementos del "derecho a acceder a información" contenidos en el artículo $1^{\circ}$ del Cpdc (desde el reconocimiento de la expresión "acceso" como "entrada, llegada, aproximación, acercamiento"62), la doctrina y la propia Ley ${ }^{63}$ enfatiza el carácter de "relevante" que posee la información que se debe entregar al consumidor. En este sentido, se define como información relevante toda aquella sin la cual no se hubiera adoptado la decisión de consumo o se hubiera efectuado en términos substancialmente distintos, siendo necesario examinar si la información omitida desnaturaliza las condiciones en que se realizó la oferta al consumidor. Precisamente, a partir de este carácter relevante, la información debe ser veraz y suficiente (no aquella estrictamente necesaria, es decir, información que va más allá de las expectativas del consumidor [Durand, 2004, p. 152]), de fácil comprensión (es decir, que no sea excesiva o sumamente compleja), apropiada y oportuna (adecuadamente suministrada, tanto por la forma como por el momento en que se proporciona [Durand, 2004, p. 152]), y fácilmente accesible, debiendo ser suministrada en idioma castellano (Maraví, 2013, p. 35). Igualmente, la doctrina identifica como mecanismos para difundir la información a la publicidad y al contrato (Maraví,

$\overline{\text { 57. Aprobado mediante Ley }} \mathrm{N}^{\circ} 29571$ del 2010.

58. Como ejemplos, tenemos las referencias sobre el deber de informar anotadas en la Ley 28300 del 2004 y en la Ley General de Salud (D.S 019-2001). 59. Concretamente, esta norma se encuentra inserta en el Título I Capítulo I del Cpdc, capitulo que reconoce los derechos del consumidor.

60. Dentro de los desarrollos normativos latinoamericanos, en torno a la protección de los derechos del consumidor como escenario de integración y construcción de identidad comunitaria (especialmente en el marco de la Comunidad Andina de Naciones CAN), la doctrina destaca la existencia de esta norma de la Constitución Política Peruana de 1993

61. De hecho, el Código del consumidor peruano identifica expresamente esta "asimetría informativa", definiéndola como la "característica de la transacción comercial por la cual uno de los agentes, el proveedor, suele tener mayor y mejor información sobre los productos y servicios que ofrece en el mercado a los consumidores" (artículo IV numeral $7^{\circ}$ Ley N² 29571 del 2010).

62. Según lo definido por el Diccionario de la Real Academia Española.

63. En efecto, dentro del ámbito normativo, la Ley N 29571 encabeza el tratamiento de la información general que se debe entregar a los consumidores, definiendo el carácter relevante que debe poseer dicha información. Véase: artículo 2² Subcapítulo I, Capítulo I, Título I, Ley No 29571 del 2010. 
2013, pp. 35-36), aclarándose que las características informadas vía publicidad son exigibles al proveedor aunque no figuren en el contrato64.

Finalmente, el Cpdc refuerza los alcances del deber general de información establecido en su artículo $1^{\circ}$ número 1.1 letra b), a partir de la aplicación de diversos preceptos, contenidos en la esfera de los principios y políticas públicas que orientan el régimen del consumidor. Estas directrices son:

En primer lugar, dentro del marco de los principios que rigen el Cpdc, tenemos el reconocimiento del "principio de la transparencia" y el "principio de corrección de asimetría", directrices que deben ser tomadas en cuenta al momento de resolver conflictos de consumidor, ya que son las bases informantes y las constantes culturales que subyacen en todo sistema jurídico para poder decidir justicia de consumo con equidad (Durand, 2011, p. 19). El primero ("principio de la transparencia"), pretende que en la actuación en el mercado, los proveedores generen una plena accesibilidad a la información a los consumidores acerca de los productos o servicios que ofrecen ${ }^{65}$. El segundo ("principio de corrección de asimetría"), se destaca no solo por reconocer expresamente la existencia de una situación de desventaja entre el consumidor y el proveedor: además, advierte la necesidad de que las normas de protección al consumidor deben corregir las distorsiones o malas prácticas generadas por la asimetría informativa ${ }^{66}$.

En segundo lugar, dentro del marco de las políticas públicas a las que se somete el Cpdc, al Estado se le otorga el rol de garantizar el derecho a la información de los consumidores, promoviendo que el sector público respectivo y el sector privado faciliten mayores y mejores espacios e instrumentos de información a los consumidores, a fin de hacer más transparente el mercado ${ }^{67}$.

Finalmente, tenemos todo un capítulo dedicado al tratamiento de la información que se debe entregar a los consumidores, en el cual se incluyen temas a referidos a su contenido, características y publicidad.

\section{El deber general precontractual de información y la protección al consumidor: el caso chileno}

En el contexto jurídico de América Latina, Chile implementó uno de los primeros modelos en sistematizar, en un solo cuerpo legal, las normas relativas a la defensa de los consumidores, lo que ocurrió con la promulgación el año de 1997 de la Ley N 19.496 , también conocida como Ley de Protección al Consumidor (en adelante LPC) ${ }^{68}$. Un aporte sustancial generado con la aprobación de esta ley, consistió en la consagración del derecho a la información a favor del consumidor (Pavan, 1997. p. 29). No obstante este reconocimiento, con base en las críticas y observaciones planteadas por la doctrina, y aprovechando la experiencia del derecho comparado, es posible formular propuestas a fin de avanzar en el perfeccionamiento de esta protección. A partir de esta premisa, a continuación examinaremos el tratamiento del deber general precontractual de información dentro del marco de la defensa del consumidor en Chile, finalizando el presente trabajo con las conclusiones generadas del estudio realizado.

64. Según lo establecido por el Instituto Nacional de Defensa de la Competencia y de la Protección de la Propiedad Intelectual, Sala de defensa de la competencia, Resolución No. 1029-2010/SC2 del 19 de mayo de 2010.

65. Principio reconocido en el artículo V número 3 Ley N 29571 del 2010.

66. Principio reconocido en el artículo V número 4 Ley $N^{\circ} 29571$ del 2010.

67. Política pública establecida en el artículo VI número 2 Ley № 29571 del 2010.

68. Ley publicada en el Diario Oficial el 7 de marzo de 1997. 
En la legislación chilena, el deber general precontractual de información es abordado por la LPC en su artículo $3^{\circ}$ letra b), norma que incluye entre los derechos básicos del consumidor, "el derecho a una información veraz y oportuna sobre los bienes y servicios ofrecidos, su precio, condiciones de contratación y otras características relevantes de los mismos, y el deber de informarse responsablemente de ellos".

El deber de informar del artículo $3^{\circ}$ letra b), se desarrolla en un conjunto de deberes específicos contenidos en la LPC. En este ámbito, la normativa chilena se encarga de dar tratamiento a diferentes materias: expendio de productos defectuosos, usados o refaccionados ${ }^{69}$; divulgación de los precios de los bienes que se expendan o de los servicios que se ofrezcan ${ }^{70}$; promociones y ofertas ${ }^{71}$; ofrecimiento de crédito directo al consumidor ${ }^{72}$; información básica comercial (es decir, los datos, instructivos, antecedentes o indicaciones que el proveedor debe suministrar obligatoriamente al público consumidor ${ }^{73}$ ) y sus características ${ }^{74}$; información adicional que se debe proporcionar en relación a los productos potencialmente peligrosos ${ }^{75}$; y publicación de la individualización del jefe del local en donde se ofrezcan bienes o servicios ${ }^{76}$.

\subsection{Estado de la cuestión del deber general precontractual de información y la protección al consumidor}

Establecer el estado de la cuestión dentro del marco normativo nacional, exige estudiar de manera sistemática dos aspectos: en primer lugar, debemos identificar las razones que justifican el deber de informar a los consumidores en el ámbito de sus relaciones de consumo, razones que fundamentan la existencia del artículo $3^{\circ}$ letra b) de la LPC. En segundo lugar, es necesario determinar los alcances de ese deber reconocido en el señalado precepto legal. El examen de estos dos factores, nos permitirá identificar las limitaciones reconocidas a la obligación de informar conforme a lo contenido en el artículo $3^{\circ}$ letra b).

\subsubsection{Justificación del artículo $3^{\circ}$ letra b) de la LPC}

Al analizar la construcción normativa del artículo $3^{\circ}$ letra b) de la LPC (complementando la aplicación del principio de la buena fe [Morales, 1988, pp. 229-231] $]^{77}$, como mecanismo para proteger la lealtad y honradez desplegada por quienes pretenden asentar una vinculación jurídica de forma seria [Barrientos, 2013, p. 97]), se evidencia que su redacción se justificó en la existencia de una asimetría informativa en la relación entre los proveedores y usuarios, asimetría que fue invocada durante todo el trámite legislativo (BCN, 1997, pp. 94, 102, 116 y 481) ${ }^{78}$. A este respecto, la doctrina reconoce que durante el trabajo parlamentario, el debate en el Congreso estuvo enfocado en la transparencia en el empleo de la información (transparencia cuya importancia aumenta en la medida en que resulte de más difícil discernimiento la relación comercial [De Verda y Beamonte, 1999, p. 88] ${ }^{79}$ ), exigencia que debe estar

69. Artículo 14, LPC.

70. Artículo 30, LPC.

71. Artículos 35 y 35, LPC

72. Artículo 37, LPC.

73. Artículo $1^{\circ}$ numeral 3, LPC,

74. Artículo 32, LPC.

75. Artículo 45, LPC.

76. Artículo $50 \mathrm{D}$, LPC.

77. Entendiendo que el principio de la buena fe impone a las partes la obligación de comunicarse.

78. En efecto, la necesidad de superar el desequilibro de la información en la relación entre consumidores y proveedores, fue planteada en las diversas fases del trámite legislativo. A este respecto, tenemos las exposiciones de los diputados Juan Carlos Latorre, Carlos Dupré Silva y Juan Martínez, y el senador Carlos Ominami Pascual.

79. Esta necesidad de la exigencia de transparencia, la expone De Verda y Beamonte en los siguientes términos: "El mismo principio de la buena fe, que exige del destinatario el deber de informar de los errores conocidos, reclama del declarante un deber de autoinformación, esto es, de desplegar una diligencia regular o media en orden al exacto conocimiento de las circunstancias determinantes de la prestación de su conocimiento ad contratum. De otro modo, so pretexto de conocer la bona fides in contrahendo, se estarían amparando comportamientos negociales negligentes (e ineficientes económicamente) a costa, quizás, de sacrificar otros intereses más dignos de protección, más valiosos socialmente, porque son generadores de riqueza". 
acompañada "de un proceso de educación del consumidor y de medidas claras y precisas de publicidad, ello dentro de un buen sistema de relación fluida entre consumidores y proveedores" (Barrientos, 2013, p. 95). Estos argumentos que respaldan la existencia del artículo $3^{\circ}$ letra b), van en sintonía con la estricta regulación de los actos sujetos a la LPC, regulación fundada en el desequilibrio que se advierte entre proveedores de bienes y servicios y los consumidores (en términos de una fuerza económica superior o muy superior, con un carácter institucional, masivo, poderoso y organizado [Aimone, 2013, p. 30]), y en la consecuente necesidad de evitar abusos en contra de los consumidores (Baraona, 1993, p. 385). No obstante lo comentado, es pertinente anotar que la protección de los derechos de los consumidores no tiene una consagración a nivel constitucional en Chile.

\subsubsection{Alcances del artículo $3^{\circ}$ (etra b) de la LPC}

Con el objetivo de superar la asimetría informacional identificada en las relaciones de consumo, el artículo $3^{\circ}$ letra b) establece un deber general precontractual de informar a favor de los consumidores. La naturaleza general de este deber (consistente en la obligación de entregar una información veraz y oportuna sobre las características relevantes de los bienes y servicios ofrecidos), surge del hecho de que esta obligación debe cumplirse en cualquier acto derivado de una relación de consumo, afectando a todos los "bienes y servicios ofrecidos" según reza la norma.

Igualmente, el deber general atribuye dos elementos a la información que debe ser proporcionada al consumidor. Por un lado, tenemos el carácter "veraz", lo cual determina la prohibición al proveedor de incurrir en imprecisiones que puedan generar confusión en los consumidores a partir de información parcial o incompleta, exigiéndose que la información otorgada sea cierta, precisa y comprobable (SERNAC, s.d., p. 2). Por otro lado, tenemos el carácter "oportuno", lo cual implica que la información sea entregada al iniciarse la relación de consumo, más precisamente durante la etapa precontractual ${ }^{80}$.Teniendo en cuenta los dos elementos que caracterizan a la información (veracidad y oportunidad), contenidos dentro del deber general estipulado en el artículo $3^{\circ}$ letra b) de la LPC, se plantea la pregunta de si el carácter veraz y oportuno es requisito suficiente para que la voluntad del consumidor se forme correctamente. Para la doctrina, pese al avance que significó el establecimiento normativo de estos dos elementos (los cuales incluso han sido aplicados a nivel jurisprudencial ${ }^{81}$ ), la respuesta a este interrogante sería negativa, atendiendo varios argumentos. En primer lugar, tenemos la naturaleza redundante del requisito de la veracidad, ya que el carácter real de la información es algo que se presupone ${ }^{82}$. En segundo lugar, se estima que la veracidad de la información es insuficiente, si esta no posee un atributo de utilidad para el consumidor (Gómez, 1980, p. 148). Adicionalmente, se exige que esta información sea comprensible, es decir, con un contenido intelectualmente accesible a un consumidor medio, sin que deba realizar un esfuerzo intelectual extraordinario o requiera la asistencia de terceros o procurarse otra información adicional (De la Maza, 2010, p.44). Finalmente, aun cuando resulta necesario que la

80. Esta obligación de informar de manera oportuna por parte del proveedor, es un factor que ya ha sido reconocido por la jurisprudencia. Por ejemplo, tenemos el recurso de casación fallado por la Corte Suprema de Justicia (Rol. 23092-2014). en el cual se ratificó la sentencia que condenaba a la empresa Inmobiliaria "Las Encinas de Peñalolén" por infracciones a la Ley del Consumidor en la construcción de viviendas. En lo central, en el considerando décimo noveno se estipuló que "los términos de la contratación mermaron la voluntad del consumidor al celebrar el contrato, por la incorporación de cláusulas abusivas que no estaba en condiciones de objetar al momento de formarse el consentimiento y por la alteración de los términos y condiciones convenidos en el acuerdo los que finalmente resultaron modificados sin que se informara de manera veraz y oportuna a los consumidores perjudicados"

81. En efecto, en el plano jurisprudencial, son varios los casos en donde se exige el cumplimiento del carácter veraz y oportuno de la información, proporcionada por el proveedor al consumidor. Al respecto, tenemos las siguientes decisiones: en primer lugar, el Rol No 9.200-2004-2 del 8-10-2008, decisión en donde el Juzgado de Policía Local de San Miguel impuso una multa a beneficio fiscal a la empresa Winter S.A. por la mala rotulación de un alimento, concretamente, la no divulgación oportuna de la fecha de elaboración de un producto; en segundo término, el Rol № 55.782-2 del 16-08-2007, en donde el Juzgado de Policía Local de Quilicura impuso una multa a beneficio fiscal a la empresa Comercial D \& S (confirmada por la Corte de Apelaciones de Santiago, Rol N ํ 5560-2007 del 21-11-2007) por no entregar de forma "inmediata" (y por ende "oportuna" y "veraz") cierta información, concretamente, las bases de un concurso; y en tercer lugar, el Rol № 2442-F del 23-03-2008, en donde el Juzgado de Policía Local de Providencia condenó a la empresa Help S.A. por no informar de manera veraz y oportuna el precio y las condiciones de contratación de los servicios ofrecidos al consumidor (en este caso, la Corte de Apelaciones de Santiago declaró desierto el recurso de apelación, según el Rol № 4274-2008 del 27-11-2008).

82. Existiendo una interdicción de la falsedad en este ámbito. 
información sea suministrada en forma oportuna al consumidor, dicho requisito se subentendería si se exigiera que la información debe resultar útil para este consumidor, utilidad que adquiere una mayor relevancia en las relaciones negociales que involucran nuevas tecnologías (Pinochet, 2004) ${ }^{83}$, gracias a la despersonalización que la contratación electrónica supone (Barrientos, 2013, p. 100).

4.2.3. Propuestas para fortalecer el deber general precontractual de informar contenido en el artículo $3^{\circ}$ (etra b) de la LPC

Dada la insuficiencia identificada respecto a los requisitos de veracidad y oportunidad que componen el deber general precontractual de informar (como herramienta que debe permitir a la parte más débil en la relación de consumo adoptar la mejor decisión a favor de sus intereses), una primera propuesta que formulamos para fortalecerlo consiste en integrar este deber general estipulado en el artículo $3^{\circ}$ letra b), con la noción de información básica comercial ${ }^{84}$, incorporando además la obligación de que esta información básica debe entregarse "en idioma castellano, en términos comprensibles y legibles"85. Esta integración entre deberes (general y específicos), además de constituir una mejora en la técnica legislativa, permitiría dar un mayor grado de precisión a la regla estipulada en el citado artículo $3^{\circ}$ letra b).

En segundo lugar, en lo que respecta al contenido de la información, el artículo $3^{\circ}$ letra b) agrega que la información que debe proporcionarse al consumidor abarca "los bienes y servicios ofrecidos, su precio, condiciones de contratación y otras características relevantes de los mismos", garantía que se extiende al consumidor financiero (Rodríguez, 2015, p. 92) ${ }^{86}$, a partir de la modificación generada con la Ley № 20.555 del $2011^{87}$, otorgando un amplio rango de cobertura a la norma. Sobre el particular, aunque no es posible enunciar taxativamente cuál es la información que un consumidor promedio necesita para formar adecuadamente su voluntad, la doctrina propone establecer ciertos mínimos que orienten al proveedor, incorporando dentro de ese catálogo alguna información que se encuentra dispersa en el articulado de la LPC. En este contexto, advirtiendo que la norma es escasa ${ }^{88}$, De la Maza (2010, p.45) sugiere agregar la información cuyo suministro impone el artículo 14 de la LPC, la cual tiene que ver con los productos que se venden con alguna deficiencia, son usados, refaccionados o en cuya fabricación se hayan utilizado partes o piezas usadas. El mismo autor, propone incorporar el deber específico anotado en el artículo 30 de la LPC, y que consiste en la obligación del proveedor de divulgar los precios de los bienes que se expendan o de los servicios que se ofrezcan.

\section{Conclusiones}

1. Al contrastar diversos modelos normativos correspondientes a las principales economías latinoamericanas (concretamente Brasil, México, Argentina, Perú y Chile), un aspecto común que se reconoce es la importancia otorgada por estos sistemas al deber general precontractual de información dentro del marco de los derechos del consumidor. Esta situación, se confirma a partir del atributo de derecho básico concedido a la

83. A este respecto, Ruperto Pinochet Olave reconoce que existe una gran cantidad de casos en que "los sujetos que negocian por medio de las nuevas tecnologías no se conocen, no se ven, ni se escuchan, por lo que la información que naturalmente pueden obtener es mínima", factor que se agrava teniendo en cuenta la dimensión internacional del comercio electrónico y la consecuente "presencia de un grado de dificultad mayor cuando se trata de conseguir información sobre el proceso negocial".

84. Deber específico actualmente reconocido en el artículo $1^{\circ}$ numeral 3 de la LPC.

85. Deber específico actualmente reconocido en el artículo 32 de la LPC.

86. El artículo $3^{\circ}$ parágrafo $2^{\circ}$ de la LPC incorporó, dentro del marco general de los derechos y deberes del consumidor, los derechos del consumidor de productos o servicios financieros. En el ámbito del deber general de informar, estos derechos del consumidor financiero incluyen la garantía de conocer el costo total del producto o servicio (artículo $17 \mathrm{G}$ de la LPC), y el derecho a ser informado por escrito de las razones (las cuales deben fundarse en condiciones objetivas) que se tienen para rechazar la contratación de un servicio financiero [artículo 17 B, letra g), de la de la LPC].

87. En efecto, en lo que respecta a la LPC, a partir de la modificación generada con la Ley No 20.555 del 28 de noviembre del 2011 (modificación que doto de atribuciones en materias financieras, entre otras, al Servicio Nacional del Consumidor) el citado estatuto describe, como parte de los derechos del consumidor de productos o servicios financieros, la información que los prestadores de este tipo de productos y servicios deben proporcionar.

88. Ya que, por ejemplo, en ella no se alude a la individualización del proveedor. 
obligación de informar a la parte más débil en las relaciones de consumo, reconocimiento que en la mayoría de los sistemas revisados tiene un respaldo de carácter Constitucional. El grado de relevancia jurídica otorgado a este deber, va en sintonía con las directrices formuladas en el denominado "Programa preliminar" europeo de 1975 (primer estatuto que reconoció formalmente el carácter fundamental del derecho a la información del consumidor), programa que serviría de base al Código de Defesa do Consumidor brasileño de 1990, punto de partida en América Latina dentro del reconocimiento formal de la importancia de informar a los consumidores. La presencia del deber general de informar examinado, se desarrolla en varios deberes específicos.

2. Al concentrarnos en el caso chileno y su regulación del deber general precontractual de información dentro del marco de la protección al consumidor, este posee varios elementos comunes con el tratamiento otorgado por los diversos sistemas de derecho comparado: el rol que cumple la asimetría informacional en las relaciones de consumo (como elemento justificador del deber de informar), el reconocimiento del carácter de derecho básico del consumidor, y la presencia de un deber general de informar que se manifiesta en varios deberes específicos. Sin embargo, una diferencia sustancial con la mayoría de los modelos comparados, es la no consagración a nivel constitucional en el ámbito de la protección de los derechos de los consumidores.

3. Finalmente, con el propósito fortalecer los alcances del deber general precontractual de informar contenido en el artículo $3^{\circ}$ letra b) de la LPC, son tres las propuestas que se formulan a fin de lograr este objetivo. En primer lugar, integrar el deber general estipulado en el artículo $3^{\circ}$ letra b) con la noción de información básica comercial (es decir, los datos, instructivos, antecedentes o indicaciones que el proveedor debe suministrar obligatoriamente al público consumidor) y sus características (la información básica debe entregarse "en idioma castellano, en términos comprensibles y legibles"), deberes particulares que actualmente se encuentran estipulados en los artículos $1^{\circ}$ numeral 3 y 32 del LPC. En segundo lugar, incorporar al catálogo de información que actualmente se debe suministrar al consumidor (y que incluye precio, condiciones de contratación y "otras características relevantes"), otros datos que se encuentran dispersos en el articulado de la LPC, como por ejemplo los incluidos en los artículos 14 y 30 del LPC. Por último, y como una pretensión más ambiciosa, conceder un reconocimiento Constitucional en materia de defensa del consumidor, aprovechando la experiencia comparada en este ámbito. 


\section{Referencias}

Asociación el poder del consumidor. Derechos a la educación y a la información. Obtenido en http://elpoderdelconsumidor.org/derechos-a-la-educacion-y-a-la-informacion/. Consultado el 10 de enero del 2020.

Asociación protección de consumidores del mercado común del sur, El consumidor y la relación de consumo. Obtenido en http://www.sic.gov.co/informacion-enganosa. Consultado el 20 de julio del 2017.

Aimone, E. (2013). Protección de derecho del consumidor. Santiago de Chile, Thomson Reuters.

Banco Mundial. PIB (US\$ a precios actuales): Todos los países y economías. Obtenido en https://datos.bancomundial.org/indicador/NY.GDP.MKTP.CD?view=chart. Consultado el 25 de enero del 2019.

Baistrocchi, E. y Rodríguez, J. (1991). «Hacia la protección del consumidor: la responsabilidad por daños al consumidor en el proyecto de ley de los doctores Atilio A. Alterinl, Roberto López Cabana y Gabriel A. Stiglitz», en Lecciones y ensayos. Universidad de Buenos Aires.

Bagalá, P. El deber de información en la ley de defensa del consumidor y su llegada al código civil y comercial. Diario Consumidores y Usuarios. Obtenido en http://www. pensamientocivil.com.ar/system/files/2015/10/Doctrina2222.pdf. Consultado el 25 de julio del 2019.

Baraona, J. (1993). La regulación contenida en la ley 19.496 sobre protección de los derechos de los consumidores y las reglas del código civil y comercial sobre contratos: un marco comparativo. Revista Chilena de Derecho, 41 (2), 381-408.

Barrientos, M. (2013). «Artículo $3^{\circ}$ B). Derecho a información veraz y oportuna», en F. Barrientos Camus (coordinadora), La protección de los derechos de los consumidores. 87-93. Santiago de Chile, Thomson Reuters.

Biblioteca del Congreso Nacional de Chile (1997). Historia de la Ley N 19.496 Establece normas sobre protección de los derechos de los Consumidores. Santiago, BCN.

De la Maza, I. (2010). El suministro de información como técnica de protección de los consumidores: los deberes precontractuales de información. Revista de Derecho Universidad Católica del Norte, 17 (2), 21-52.

De la Maza, I. (2013a). «Artículo $1^{\circ}$ №3. Definición información básica comercial», en F. Barrientos Camus (coordinadora), La protección de los derechos de los consumidores. 24-31. Santiago de Chile, Thomson Reuters.

De la Maza, I. (2013b). «Artículo 17 B (Letras a, b, c, d, e, f). Especificaciones contratos de adhesión servicios crediticios», en F. Barrientos Camus (coordinadora), La protección de los derechos de los consumidores. 376-398. Santiago de Chile, Thomson Reuters.

De la Maza, I. (2013c). «Artículo 28. Inducción a error o engaño del mensaje publicitario», en F. Barrientos Camus (coordinadora), La protección de los derechos de los consumidores. 674-684. Santiago de Chile, Thomson Reuters.

De Verda y Beamonte, J. (1999). Error y responsabilidad en el contrato. Valencia, Tirant lo Blanch.

Durand, J. (2004). El derecho del consumidor como disciplina jurídica autónoma. Tesis doctoral. Lima, PUC.

Durand, J. (2011). Los vacíos del Nuevo Código de Protección y Defensa del Consumidor y su repercusión en los derechos del consumidor. Lima, Universidad San Martin de Porres.

Edicom Data. Etiquetado transgénicos: diferencias Europa-USA. Obtenido en http:// www.rg1169.eu/etiquetado-transgenicos-diferencias-europa-usa/. Consultado el 20 de agosto del 2019. 
Escalona, E. I. (2013). «Artículo 37. Normas de crédito y cobranzas», en F. Barrientos Camus (coordinadora), La protección de los derechos de los consumidores. 813826. Santiago de Chile, Thomson Reuters.

Fernández, F. (2013). «Artículo 17 L. Sanción a la inducción a error por parte de los proveedores de servicios financieros», en F. Barrientos Camus (coordinadora), La protección de los derechos de los consumidores. 504-512. Santiago de Chile, Thomson Reuters.

Fernández, M. (2004). «La normativa sobre el etiquetado de los transgénicos en la U.E. y sus efectos sobre el bienestar», en M. S. de Tomás Morales y C. Heller del Riego (coordinadores), El día de Europa. Las transformaciones de la Unión Europea: la ampliación y la Convención Europea. Madrid, UPCICAI ICADE).

Gallo, P. (2007). Asimmetrie informative e doveri di informazine. Rivista di diritto civile, 53 (2).

Gómez, J. (1980). Notas sobre el derecho de información del consumidor. Revista Jurídica de Cataluña, 3, 699-724.

Isles, E. (2013). «Artículo 29. Multa por la omisión o falta a la verdad», en F. Barrientos Camus (coordinadora), La protección de los derechos de los consumidores. 685-778. Santiago de Chile, Thomson Reuters.

Maraví, A. (2013). Breves apuntes sobre el sistema de protección al consumidor en el Perú. Revista de Actualidad Mercantil, 2, 31-40.

Miragem, B (2016). Curso de direito do consumidor. $6^{a}$ edição, São Paulo, Thomson Reuters.

Morales, A (1988). El error en los contratos. Madrid, Ceura.

Nieto, A. (1986). Competencias de las Diputaciones provinciales en materia de consumo. Estudios sobre consumo, 8.

ONU (2016). Directrices para la protección del consumidor. Ginebra, ONU.

Ovalle, J. (2000). Derechos del consumidor. México D.F., UNAM.

Ovalle, J. (2005). Los derechos de los consumidores. Revista de Derecho Privado, 12, $75-111$

Pasa, B. (2007). Primeras reflexiones sobre el Codice del consumo italiano. Anuario de derecho civil, 60 (3), 1307-1317.

Pavan, L. (1997). La protección del consumidor en el Mercosur. Buenos Aires, Instituto Nacional de la Administración Pública.

Pinochet, R. (2004). La formación del consentimiento a través de las nuevas tecnologías de la información. Parte I: la oferta electrónica. Revista lut Ex Praxis 10 (2). Obtenido en https://scielo.conicyt.cl/scielo.php?script=sci arttext\&pid=S0718-00122004000200009\#nota92, consultado el 5 de junio del 2018].

Piris, C. (2000). Evolución de los derechos del consumidor. Resistencia, Argentina, UNNE.

Prada, J. (1998). Protección del consumidor y responsabilidad civil. Madrid, Marcial Pons.

Procuraduría Federal del Consumidor (s.d). Introducción a PROFECO. México D.F., PROFECO.

Reyes, A. y García, L. (2016). Esfuerzos latinoamericanos en torno a los derechos del consumidor: CAN y MERCOSUR. Revista Relaciones Internacionales, Escuela de Relaciones Internacionales. Universidad Nacional, Costa Rica 89 (1), 171-190.

Rodríguez, P. (2015). Derecho del consumidor: estudio crítico. Santiago de Chile, Thomson Reuters.

Roscoe L. y Faiad de Moura, W. (2014). Manual de direito do consumidor. Brasilia, Ministério da Justiça.

Sánchez de Diego Fernández de la Riva, M. (2009). Consumidores y Derecho a la Información. Prospectiva desde el Derecho Constitucional: El derecho de acceso a la información pública. Madrid, Consejo Económico Social. 
Sernac. Guía de alcance jurídico. Uso de sello SERNAC y logo SERNAC financiero. Obtenido de www.sernac.cl/category/estudios/>, consultado el 9 de octubre del 2017.

Stiglitz, G. (1994). Defensa de los consumidores de productos y servicios. Buenos Aires, Ediciones La Rocca.

Universidad Interamericana para el Desarrollo (s.d.) Análisis del consumidor. México D.F., UNID.

Zurilla, M. (s.d.). El derecho de información del consumidor en los contratos con consumidores y usuarios, en el nuevo texto refundido de la ley general para la defensa de consumidores y usuarios. Universidad de Castilla-La Mancha. 